\title{
O substrato histórico material para uma reflexão da relação entre Design e Educação
}

Fabiana Marques Jeremias Leite Vaz Doutoranda em Educação pela UNICAMP

\section{Resumo}

Nesta breve comunicação, buscamos reconstituir, dialética e politicamente, os contextos históricos da produção institucional do Design Industrial diante dos processos econômicos e sociais da eclosão e afirmação do modo de produção capitalista e seus mecanismos materiais e sócio-políticos, a partir do manejo e consideração das categorias, conceitos e formas de analisar determinado fenômeno, próprias do campo da Filosofia da Educação.

Palavras-chave: Design Industrial, Educação; Marxismo.

\begin{abstract}
This communication, we seek to reconstruct, dialectic and politically, the historical contexts of institutional production of Industrial Design on the economic and social processes of emergence and affirmation of the capitalist mode of production and their material mechanisms and socio-political, from the handling and consideration categories, concepts and ways to analyze a given phenomenon, peculiar to the field of Philosophy of Education.
\end{abstract}

Keywords: Industrial Design; Education; Marxism. 


\section{Introdução}

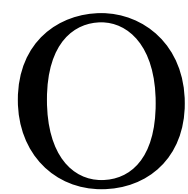

presente texto pretende estabelecer orientações e fundamentos para uma reflexão crítica, no âmbito da Filosofia da Educação sobre a atividade criativa, projetual - surgida a partir da Revolução Industrial, enquanto uma área especializada na concepção de produtos industriais - definida genericamente pelo termo inglês “design" e, principalmente, sobre sua interdependência histórica com o processo educacional escolar moderno e seus desdobramentos éticos, estéticos e políticos no cenário contemporâneo.

A premissa que nos embasa, nessa tarefa investigativa, parte da legitimidade incontestável do design industrial, como atividade criativa e projetual, que ganhou contornos mais definidos em meio à Revolução Industrial, desde os primórdios do século XVIII, ganhando maiores projeções nos dois séculos seguintes, com o desenvolvimento da divisão social do trabalho ${ }^{1}$ e com a implementação da máquina-ferramenta ${ }^{2}$ no interior das indústrias modernas. Não nos restam dúvidas quanto à onipresença dos resultados do desenvolvimento do design industrial, materializados desde os mais simples objetos (mercadorias), que povoam e ocupam nosso cotidiano, como um lápis, uma cadeira, um copo, até mesmo os mais complexos sistemas de informação visual, de locomoção, entretenimento e equipamentos de alta tecnologia, utilizados nos mais variados campos e atividades do mundo contemporâneo. Temos como basilar a pressuposição de que o design industrial, pela própria identidade, nasceu das entranhas da racionalização produtiva empreendida pela revolução industrial burguesa e seus desdobramentos.

\footnotetext{
1 Acha, inicia o capítulo sexto de sua obra, intitulado "Los diseños" com a seguinte orientação: "Los diseños tampoco nacieron hechos y derechos; al igual que las artes y que las artesanías, son también frutos de una nueva división técnica del trabajo estético especializado que comezó a germinar cuando la cultura estética de Occidente necesitó profesionales capaces de introducir recursos estéticos en los productos industriales” (1988: 75).

2 Segundo Marx, a máquina-ferramenta é um mecanismo “(...) que ao lhe ser transmitido o movimento apropriado, realiza com suas ferramentas as mesmas operações que eram antes realizadas pelo trabalhador com ferramentas semelhantes” (1980: 426).
} 
Segundo Cardoso, a palavra design tem suas origens mais recentes na tradição da língua inglesa e tal substantivo remete à noção de concepção, planejamento, ideia, projeto e intenção. Dialeticamente remete também à noção de configuração, arranjo e estrutura (2004:14). Já suas origens mais longínquas proveem do latim, cujo verbo e radical designare remete também a uma noção ambígua que articula, na mesma atividade, duas dimensões distintas: designar e desenhar. Podemos deduzir desta breve apresentação que a palavra design, em termos estritamente etimológicos, suscita uma atividade que condensa duas dimensões que, nos atuais moldes do desenvolvimento das forças produtivas, são consideradas como completamente estranhas e até mesmo opostas entre si; ou seja, estamos nos referindo à atividade de conceber e à atividade de executar um determinado produto.

\section{Design Moderno e Educação Escolar}

São muito tênues as distinções entre a história do design industrial moderno e a história de seu ensino. Fruto da especialização do trabalho industrial, o design tal qual conhecemos hoje, engendrado a partir da hipertrofia do trabalho intelectual em detrimento do trabalho manual, teve sua identidade cristalizada e disseminada pelos quatro cantos do mundo após a criação da Escola de Artes e Ofícios Bauhaus, em 1919, na cidade de Weimar, na Alemanha ${ }^{3}$.

Com relação ao surgimento do profissional designer, e as suas vinculações com um posterior projeto educacional, Cardoso nos diz:

Os primeiros designers, os quais têm permanecido geralmente anônimos, tenderam a emergir de dentro do processo produtivo e eram aqueles operários promovidos por seus quesitos de experiência ou habilidades a uma posição de controle $e$ concepção, em relação às outras etapas da divisão de trabalho. A transformação dessa figura de origens operárias em um profissional liberal, divorciado da experiência produtiva de uma

\footnotetext{
3 Para maior compreensão desta Escola, recomendamos a leitura de a Pedagogia da
} Bauhaus de Rainer Wick (1989). 
indústria especifica e habilitado a gerar projetos de maneira genérica, corresponde a um longo processo evolutivo que teve seu inicio na organização das primeiras escolas de design no século 19 e que continuou com a institucionalização do campo ao longo do século 20 (2004: 16) (grifo meu).

A compreensão desta simbiose existente entre o design industrial e a educação escolar ${ }^{4}$ moderna é de extrema importância para nossa reflexão, pois a tradição do pensamento crítico dialético, fundamentado no materialismo histórico, revela em larga medida que “a educação é um dos elementos básicos da estrutura social, e como instituição torna-se a estrutura ideológica mais importante para a reprodução e manutenção dos grupos sociais” (Nunes, 1996: 16).

Marx (1980), em sua discussão sobe A Maquinaria e a Indústria Moderna, em “O Capital”, nos dá pistas indispensáveis e determinantes para a compreensão desta simbiose existente entre o desenvolvimento industrial - e dentro deste movimento precisamos estar atentos para os desdobramentos que fornecem as condições materiais necessárias para o surgimento do design moderno - e a necessidade de educar, ou seja, de sistematizar os conhecimentos depreendidos deste processo evolutivo da indústria, e posteriormente transmiti-los às classes que futuramente se ocupariam destas atividades industriais.

O movimento dialético da simbiose - indústria, design e educação enraíza-se na base técnica revolucionária da indústria moderna. Segundo Marx (1980), a indústria moderna "nunca considera nem trata como definitiva a forma existente de um processo de produção” (Idem: 557). Neste sentido, seu movimento é contínuo e ascendente, bastante distinto dos antigos modos de produção manufatureira, tidos como mais conservadores e solidificados. Não obstante, a indústria moderna

\footnotetext{
${ }^{4}$ A palavra escola, segundo Saviani (2005:248), tem origem grega e significa lugar do ócio e seu nascimento coincide com a apropriação privada da terra. Há diferentes e diversas teorias históricas sobre a origem da escola. Adotamos a concepção de que a escola se constituiu como uma instituição voltada para a reprodução das habilidades e dispositivos materiais e simbólicos próprios da classe social que a constituiu: a aristocracia agrária escravista antiga.
} 
(...) revoluciona constantemente a divisão do trabalho dentro da sociedade e lança ininterruptamente massas de capital e massas de trabalhadores de um ramo de produção para outro. Exige, por sua natureza, variação do trabalho, isto é, fluidez das funções, mobilidade do trabalhador em todos os sentidos (Idem: 558) (grifo meu).

Torna-se lei geral e social da produção industrial, a variação e a versatilidade dos trabalhadores. Com a introdução da maquinaria na indústria moderna era questão decisiva para sua fruição, substituir aqueles indivíduos acostumados aos primeiros formatos das produções capitalistas, seriadas, manufatureiras, ou seja, aqueles indivíduos que ocupavam uma posição operacional miserável, repetitiva e simplificada; por um indivíduo integralmente desenvolvido, adaptado à volatilidade deste novo modo de produção, que produz e se auto reproduz ininterruptamente. Reside justamente nesta breve digressão que descrevemos, a base históricomaterial que impulsionou o desenvolvimento e surgimento da atividade caracterizada como design industrial. É necessariamente desta característica revolucionária da indústria, desta mobilidade e transformação constante de seus processos, da migração subserviente de seus trabalhadores para novas funções que acaba por outorgar para alguns restritos operários - portadores de algumas habilidades específicas depreendidas deste contínuo movimento - a alforria do trabalho meramente operacional, mecânico e manual e de conduzi-lo para uma atividade de controle, de resolução dos problemas produtivos, melhor dizendo, de conduzi-lo para um trabalho de planejamento, de controle e concepção, desvinculado de soberania no manejo de seus impactos e potenciais resultados.

Contudo, o esforço teórico de conceituar o design industrial a partir da especialização do trabalho em meio ao desenvolvimento da indústria e de entendê-lo como categoria mediadora entre seres humanos e natureza, não é algo que nunca tenha sido feito por teóricos do design, pelo contrário, os autores Juan Acha (1988), Rafael Cardoso (2004), Bürdek (2006), entre outros, também aproximaram-se conceitualmente desta problemática. Destarte, o que nos chama a atenção e que nos impele à construção de uma posição contraposta, é a abordagem sempre positiva e desprovida de crítica 
sobre o desenvolvimento histórico do trabalho mediante o capital ${ }^{5}$. Assim, Löbach (2001), nos servirá de exemplo basilar para ilustrar como esta abordagem tem sido construída no universo acadêmico do design industrial, uma vez que, no segundo capítulo de sua obra, intitulado "Fundamentos da configuração objetual”, podemos observar claramente este direcionamento conceitual primeiramente no item "2.1 - O homem. Necessidades, aspirações”; e posteriormente no item “2.2 - Trabalho. Materialização”. No primeiro tópico o autor nos traz a sua definição de necessidade alegando que esta “(...) tem origem em alguma carência e dita o comportamento humano visando à eliminação dos estados não desejados” (2001:26) e mais adiante conclui que "a satisfação de necessidades pode, portanto, ser considerada como a motivação primária da atuação do homem” (idem, ibidem). Por sua vez, no segundo tópico o autor inicia sua reflexão da seguinte maneira:

Denominamos trabalho ao processo de transformação por meio do qual uma idéia se transforma em objetos de uso para a satisfação de necessidades. (...) Esta identidade entre o reconhecimento de uma necessidade e a materialização de uma idéia no processo de trabalho, efetuado por uma pessoa, é típica da produção para atender a necessidades próprias, porém não é mais utilizada em nossa sociedade industrial. Nela as necessidades de determinados grupos são pesquisadas por empresas industriais e o resultado é traduzido na produção de mercadorias produzidas em massa (idem: 31 ).

Em outras palavras, a reflexão descrita acima pelo autor, evidencia tanto o conceito de necessidade $e^{6}$, como o conceito de trabalho suspensos da realidade histórica, e ao manterem-se suspensos neste patamar abstrato, supratemporal, toda a possibilidade de compreensão de tais conceitos munidos de seus princípios de contradições internas é extraída. Entendemos

\footnotetext{
${ }^{5}$ Para Marx o capital é “o poder de governo (Regierungsgewalt) sobre o trabalho e seus produtos. O capitalista possui esse poder, não por causa de suas qualidades pessoais ou humanas, mas na mediada em que ele é proprietário do capital. O poder de comprar (Kaufende Gewalt) do seu capital, a que nada pode se opor, é o seu poder” (2004:40).

${ }^{6}$ Segundo Ranieri o conceito de necessidade (Notwendigkeit), difere-se do conceito de carência (Bedürfnis), sendo este último repousado sobre a base da "condição biológica do ser humano (comer, beber, dormir, habitar), o que a vincula a uma falta, assim como também a um desejo, ou seja, a carência se revela como um componente que, uma vez satisfeito, pode dar, inclusive, origem à positividade de novas carências, mais sofisticadas" (2004:17). Já o primeiro conceito está vinculado “à necessidade lógica, oposta à contingência, que aparece como possibilidade efetiva de realização a partir da satisfação histórica das carências” (idem, ibidem) (grifo meu).
} 
que ocultar, ou desconsiderar as contradições pertinentes a um determinado fato ou processo, significa abortar intencionalmente, ou ideologicamente, toda a potencialidade transformadora deste mesmo processo. Não obstante, o design industrial erigido sobre estas bases que silenciam as contradições do desenvolvimento dos processos do trabalho, só pode originar uma atividade portadora do estranhamento ${ }^{7}$ e com ela uma classe social incapaz de autogestão política revolucionária, direcionadas à emancipação humana.

Portanto, retomando a questão da volatilidade da indústria moderna, podemos concluir com as reflexões supra descritas, que nem todo operário circunscrito nessa lógica, alcançaria no percurso de um determinado tempo, ou após certo número de ocupações acumuladas no processo produtivo, um posto de controle e concepção; pelo contrário, o capital e seus movimentos são perversos e contraditórios. Esta metamorfose da indústria moderna, segundo Marx:

(...) elimina toda tranqüilidade, solidez e segurança da vida do trabalhador, mantendo-o sob a ameaça constante de perder os meios de subsistência ao ser-lhe tirado das mãos o instrumental de trabalho, de tornar-se supérfluo, ao ser impedido de exercer sua função parcial; como essa contradição se patenteia poderosa na hecatombe ininterrupta de trabalhadores, no desgaste sem freio das forças de trabalho e nas devastações da anarquia social. (1980: 558).

Temos então que, o emprego da maquinaria na indústria moderna condensa um aspecto positivo, ou seja, aquele que pelo próprio desenvolvimento tecnológico industrial faz necessária a formação integral do trabalhador, como veremos logo a seguir; e um aspecto negativo, cujo qual não se pode perder de vista, a produção da mais valia ${ }^{8}$, que segundo

\footnotetext{
7 Jesus Ranieri (2004) diferencia o conceito de alienação (Entäusserung) ao de estranhamento (Entfremdung), visto que estes conceitos, segundo este autor, ocupam lugares distintos no sistema teórico desenvolvido por Marx; sendo a alienação entendida como exteriorização, como "momento de objetivação humana no trabalho, por meio do produto resultante de sua criação” (2004:16). Já o estranhamento “é objeção socioeconômica à realização humana, na medida em veio, historicamente, determinar o conteúdo do conjunto das exteriorizações - ou seja, o próprio conjunto de nossa socialidade - através da apropriação do trabalho, assim como da determinação dessa apropriação pelo advento da propriedade privada” (idem, ibidem).

${ }^{8}$ De acordo com Marx (1980), a "mais valia se origina de um excedente quantitativo de trabalho, da duração prolongada do mesmo processo de trabalho (...)” (idem:222). É
} 
Marx “constitui o fundamento do sistema capitalista (...)” (1980:585). Estes são alguns dos elementos históricos que estão na base do design industrial tal qual conhecemos hoje. Nesta atividade se condensam disposições tão complexas, quanto contraditórias, sua face é a mesma do capital industrial, portanto é mister saber que: “(...) o desenvolvimento das contradições de uma forma histórica de produção é o único caminho de sua dissolução e do estabelecimento de uma nova forma” (Marx, 1980:559). Deste modo, pouco nos importa de fato no campo do ensino de design industrial, a simples negação da indústria, ou sua mera afirmação positiva, como único caminho possível para o desenvolvimento das relações humanas; ao contrário, temos como singular preocupação, evidenciar as contradições internas deste processo histórico a fim de buscar sua superação.

Vejamos então com mais cuidado, os movimentos internos ocorridos com o emprego da máquina-ferramenta no interior do processo produtivo industrial moderno.

No modo de produção manufatureiro a contradição expressava-se na dinâmica necessária da divisão e na exploração maximizada da força de trabalho. Já no modo de produção industrial moderno, a superação transformadora se deu no instrumental de trabalho. Precisamos então, entender como as ferramentas se transformaram em máquinas, e no decorrer deste processo, necessitamos compreender como o homem se converteu em mera força motriz da máquina-ferramenta, despojado de suas capacidades intelectuais criativas e condenado ao trabalho braçal e repetitivo. Este trajeto nos ajudará desmistificar os mecanismos que levaram o capital industrial à exploração da força de trabalho infantil e feminina em conjunto com a

possível compreender a mais valia em dois níveis distintos, porém inter-relacionados, a mais valia absoluta e a mais valia relativa. Segundo Marx, "A produção da mais valia absoluta se realiza com o prolongamento da jornada de trabalho além do ponto em que o trabalhador produz apenas um equivalente ao valor de sua força de trabalho e com a apropriação pelo capital desse trabalho excedente” (1980: 585). Já a mais valia relativa pressupõe "que a jornada de trabalho já esteja dividida em duas partes: trabalho necessário e trabalho excedente. Para prolongar o trabalho excedente, encurta-se o trabalho necessário com métodos que permitem produzir-se em menos tempo o equivalente ao salário" (idem, ibidem). 
necessidade de desenvolvimento de uma educação politécnica ${ }^{9}$. Assim poderemos prosseguir e captar os condicionantes históricos que deram origem a primeira escola de design, a Bauhaus, no início do século XX.

Segundo Marx (1980), a maquinaria moderna é constituída pela articulação laboral de três elementos distintos: o motor, a transmissão e a maquina-ferramenta. O motor é a força motriz elementar, sem a qual nada é possível. Esta força motriz pode ser oriunda de um motor a vapor, elétrico, de força animal, eólica, hidráulica, entre outras. A transmissão, por sua vez, é constituída por alavancas, correias, engrenagens, barras, turbinas e são estes elementos, condutores diretos e tradutores indiretos de movimentos mecânicos. Tanto o motor, como a transmissão, existem única e exclusivamente para fazer mover a máquina-ferramenta, e esta, por sua vez,

(...) se apodera do objeto de trabalho e o transforma de acordo com o fim desejado. É desta parte da maquinaria, a maquinaferramenta, que parte a revolução industrial no séc XVIII. E a máquina-ferramenta continua a servir de ponto de partida sempre que se trata de transformar um ofício ou manufatura em exploração mecanizada (Marx, 1980: 426).

A maquina-ferramenta é segundo Marx, uma substituição potencializada do trabalho manual humano, e neste sentido, “(...) ao lhe ser transmitido o movimento apropriado, realiza com suas ferramentas as mesmas operações que eram antes realizadas pelo trabalhador com ferramentas semelhantes” (idem, ibidem). Uma vez que a exploração mecanizada substitui o trabalhador, que antes operava um único instrumento, por um arsenal que opera inúmeras ferramentas ao mesmo

\footnotetext{
${ }^{9}$ Segundo Saviani (2005:237), "o conceito de politecnia está no centro da concepção socialista de educação. Implica a união entre instrução intelectual e trabalho produtivo”. O pensador italiano Mário Alighiero Manacorda (2007), após minuciosos estudos filológicos da obra de Marx, conclui que a expressão "educação tecnológica" traduziria com mais precisão a concepção marxiana do que o termo "educação politécnica”. Nós, assim como Saviani, acreditamos que "do ponto de vista conceitual, o que está em causa é um mesmo conteúdo. Trata-se da união entre formação intelectual e trabalho produtivo" (idem:238). Uma vez que estes termos segundo Saviani podem ser considerados como sinônimos, concordamos com a idéia de que "enquanto o termo "tecnologia" foi definitivamente apropriado pela concepção dominante, o termo "politecnia" sobreviveu apenas nas denominações de algumas escolas ligadas à atividade produtiva (...) assim, a concepção de politecnia foi preservada na tradição socialista sendo uma das maneiras de demarcar essa visão educativa em relação àquela correspondente à concepção burguesa dominante (idem,ibidem).
} 
tempo e que apenas necessita de uma força motriz para colocar-se em funcionamento, esta pode ser de múltiplas naturezas, inclusive humana e “(...) podem tomar seu lugar o vento, a água, o vapor etc., e torna-se acidental o emprego da força muscular humana como força motriz” (idem: 428).

Diante deste quadro, a força muscular humana era tão necessária quanto supérflua, visto que outros dispositivos poderiam substituí-la com facilidade, e não tardou para que o trabalho braçal humano (masculino e adulto) fosse substituído pela mão de obra de crianças e mulheres. Uma leitura mais detalhada do capítulo XIII, parte 3 (Consequências Imediatas da Produção Mecanizada Sobre o Trabalhador), da obra "O Capital”, revela os mecanismos perversos de exploração do trabalho infantil e feminino, que elevaram o número de assalariados no interior do processo produtivo na mesma medida que desvalorizou o trabalho do homem adulto. Mostra também a revolução que este processo causou no contrato entre o capitalista e o trabalhador, uma vez que este se tornou não só vendedor de sua força de trabalho, mas também de seus filhos e mulheres. Porém, não podemos nos estender demasiadamente nestas discussões, embora queiramos, pois é necessário prosseguir e ir direto ao ponto em que este processo nos remete à questão educacional.

A exploração do trabalho levada aos limites, que transformou crianças e jovens em meras máquinas produtoras de mais valia resultou em uma degradação moral e ao que Marx caracterizou como obliteração intelectual dos adolescentes. Não há na história precedente de tamanha oclusão espiritual entre os jovens e tais consequências eram extremamente nocivas ao próprio desenvolvimento produtivo. Diante deste quadro, esta inadequação das capacidades intelectuais dos jovens - gerada pela fragmentação do processo de trabalho - para com a nova condição da indústria moderna "forçou o Parlamento inglês a fazer da instrução elementar condição compulsória para o emprego produtivo de menores de 14 anos em todas as indústrias sujeitas às leis fabris” (Marx, 1980: 456) (grifo meu). Assim, encontramos na base material da indústria moderna - ou 
seja, aquela que se caracteriza pela implementação da maquina-ferramenta no setor produtivo - não só os elementos característicos para a constituição do design industrial moderno, como já descrevemos anteriormente, mas também o desenvolvimento espontâneo das escolas politécnicas. Bem entendido, tornou-se questão crucial para o desenvolvimento das relações de produção capitalistas,

(...) substituir o indivíduo parcial, mero fragmento humano que repete sempre uma operação parcial, pelo indivíduo integralmente desenvolvido para o qual as diferentes funções sociais não passariam de formas diferentes e sucessivas de sua atividade (1980:559).

Eis o fulcro engendrador da escola burguesa, escola esta que nascida da apropriação e especialização do trabalho pelo capital - em específico da separação entre concepção e execução - não poderia deixar de refletir em suas formas mais triviais as antinomias deste processo, ou seja, aquelas que dividem os homens em dois grupos de interesses opostos: "aquele das profissões manuais para as quais se requeria uma formação prática limitada à execução de tarefas mais ou menos delimitadas

(...) e aquele das profissões intelectuais para as quais se requeria domínio teórico amplo a fim de preparar as elites e representantes da classe dirigente para atuar nos diferentes setores da sociedade" (Saviani, 2005:232) (grifo meu).

E ousamos ir um pouco mais além afirmando que no eito da primeira divisão estão as escolas primárias e fundamentais profissionalizantes e no âmbito da segunda divisão, ou seja, a da educação voltada para a formação intelectual, estão as academias e universidades ${ }^{10}$.

Defendemos no início deste tópico a ideia de uma díade simbiótica que envolve o design e a educação escolar. Tanto o design quanto a educação escolar se enraízam com a mesma intensidade no substrato da especialização técnica do trabalho gerada pelo desenvolvimento das forças produtivas da indústria moderna. Ora, se quisermos compreender o real

${ }^{10}$ O autor Juan Acha (1988:59) aponta como característica distintiva do designer, em relação ao artesão e ao artista, justamente a formação universitária deste profissional, uma vez que os artistas formam-se em academias e os artesãos empiricamente. 
significado e consequências desta simbiose, necessitamos aceitar que ambas as atividades foram geradas no seio da propriedade privada dos meios de produção e que por este motivo velam internamente em suas disposições efetivas, interesses de classes antagônicas. Não obstante, se o designer industrial se caracteriza por ser um profissional cuja principal atividade volta-se para a concepção de produtos industriais, que serão executados pelas mãos de outros homens (operários), assim, não é de se admirar que estes tenham que ser formados em universidades, ou academias especializadas. E em obediência as demandas produtivas do início do século XX, decorre a construção da Bauhaus.

Dedicamos especial atenção nesta reflexão, à compreensão da natureza e gênese da sociedade industrial e, no cerne de suas contradições, à emergência do trabalho moderno, ao surgimento da escola e à dinâmica do desenvolvimento de determinadas relações de produção e reprodução social. Nessa consideração buscamos reconhecer o contexto e identidade do surgimento do design industrial como necessidade e materialização dos mecanismos e formas de expressão da cosmovisão burguesa.

Na matriz que nos inspira não há a preclara predisposição de estreiteza ou maniqueísmo. Compreendemos, igualmente, a construção institucional do design e, concomitante às necessidades de reprodução do capital, o movimento que produziu a identidade da escola moderna e suas finalidades como o terreno histórico e palco político de nossa análise.

Trata-se de, ao final desta inconclusa e complexa reflexão, ratificar que o reconhecimento dessas identidades políticas e institucionais não implica na adoção de um reducionismo histórico. A investigação dos marcos e diretrizes regulatórias da gênese e conformação do campo e identidade do design, a partir da proeminência das utopias pedagógicas da Bauhaus, deverá constituir a possibilidade de engendramento de novas articulações analíticas e propositivas, tanto para a elucidação política do design e suas motivações históricas quanto para a superação das mesmas sob novas forças 
sociais, empreendidas por uma perspectiva de resistência, numa sociedade marcada por radicais estruturas de classe.

\section{Referências Bibliográficas}

ABBAGNANO, Nicola. Dicionário de Filosofia. São Paulo: Martins Fontes, 2000.

ACHA, Juan. Introducción a la Teoría de los Diseños. México: Editorial Trillas, 1988.

BOSI, Alfredo. Dialética da Colonização. São Paulo: Companhia das Letras, 2005.

CARDOSO, Rafael. Uma introdução à história do design. São Paulo: Edgard Blücher, 2004.

CHAVES, Norberto. El Oficio de Diseñar: Propuesta a la conciencia crítica de los que comienzan. Barcelona: Editorial Gustavo Gili, 2001.

CHIZZOT'TI, Antonio. Pesquisa em ciências humanas e sociais. São Paulo: Cortez, 2005.

CO, Francesco Dal. El Arquitecto em La Lucha de Classe y Otros Escritos: H. Meyer. Barcelona: Editorial Gustavo Gili, 1972

DALAROSA, Adair Ângelo. Globalização, Neoliberalismo e a Questão da Transversalidade. In: LOMBARDI, José Claudinei. Globalização, Pós-modernidade e Educação: história, filosofia e temas transversais. Campinas, SP: 2003.

DROSTE, Magdalena. Baubaus 1919-1933. São Paulo: Taschen, 1994.

ENGELS, Friedrich. A Situação da Classe Trabalhadora na Inglaterra. São Paulo: Boitempo Editorial, 2008.

FRIGOTTO, Gaudêncio. O Enfoque da Dialética Materialista Histórica na Pesquisa Educacional. In: FAZENDA, Ivani. Metodologia da Pesquisa Educacional. São Paulo: Cortez, 2008.

GOLDMANN, Lucien. Dialética e Cultura. Rio de Janeiro: Paz e Terra, 1967.

GRAMSCI, Antonio. Concepção Dialética da História. Rio de Janeiro: Civilização Brasileira, 1978.

JAMESON, Fredric. A Virada Cultural: reflexões sobre o pós-moderno. Rio de Janeiro: Civilização Brasileira, 2006.

KOPP, Rudinei. Design Gráfico Cambiante. Santa Cruz do Sul: EDUNISC, 2004. 
LÖBACH, Bernd. Design Industrial: Bases para a configuração dos produtos industriais. São Paulo: Editora Bluncher, 2001.

MANACORDA, Mário Alighiero. Marx e a Pedagogia Moderna. Campinas - SP: Editora Alínea: 2007.

MARX, Karl. O Capital: Livro I, Vol.1. Rio de Janeiro: Civilização Brasileira, 1980.

Fontes, 2003.

Contribuição à Crítica da Economia Politica. São Paulo: Martin Manuscritos Econômico-Filosóficos. São Paulo: Boitempo Editorial, 2004.

O Dezoito Brumário de Louis Bonaparte. São Paulo: Centauro

Editora, 2006.

MARX, Karl \& ENGELS, Friedrich. A Ideologia Alemã. São Paulo: Martin Claret, 2005. . A Ideologia Alemã. São Paulo: Boitempo Editorial, 2007

MATIAS, Iraldo Alberto Alves; MATIAS; Rui Carlos Alves. "Crise Ambiental" $e$ "Sustentabilidade": princípios para uma crítica à Ecologia Politica. In: Cadernos Cemarx, XXX, XX Campinas: Unicamp, 2009. NO PRELO.

NIEMEYER, Lucy. Design no Brasil: origens e instalação. Rio de Janeiro: 2 A B Editora ltda, 1998.

NUNES, César. Filosofia, Sexualidade e Educação: as relações entre os pressupostos éticosociais e histórico-culturais presentes nas abordagens institucionais sobre a educação sexual escolar. Tese de Doutoramento. Fe/Unicamp, Campinas, SP: 1996.

PAPANEK, Victor. Arquitetura e design: ecologia e ética. Lisboa: ED, 1997.

RANIERI, Jesus. Sobre os Chamados Manuscritos Econômico-Filosóficos de Karl Marx. In: Manuscritos Econômico-Filosóficos. São Paulo: Boitempo Editorial, 2004.

ROMERO, Daniel. Marx e a Técnica: Um estudo dos manuscritos de 1861-1863. São Paulo: Expressão Popular, 2005

SÁNCHEZ GAMBOA, Sílvio. A Dialética na Pesquisa em Educação: elementos de contexto. In: FAZENDA, Ivani. Metodologia da Pesquisa Educacional. São Paulo: Cortez, 2008.

SÁNCHEZ VÁZQUEZ, Adolfo. As Idéias Estéticas de Marx. Rio de Janeiro: Paz e Terra, 1968. 
SANFELICE, José Luis. Pós-Modernidade, Globalização e Educação. In: LOMBARDI, José Claudinei. Globalização, Pós-modernidade e Educação: história, filosofia e temas transversais. Campinas, SP: 2003.

SAVIANI, Dermeval. Educação: Do Senso Comum à Consciência Filosófica. Campinas, SP: Autores Associados, 2004.

- Educação Socialista, Pedagogia Histórico-Crítica e os Desafios da Sociedade de Classes. In: LOMBARDI, José Claudinei, SAVIANI, Dermeval. Marxismo e Educação: debates contemporâneos. Campinas, SP: Autores Associados, 2005.

2005.

Pedagogia Histórico-Crítica. Campinas, SP: Autores Associados,

TAMBINI, Michael. O Design do Século. São Paulo: Editora Ática, 1999.

WICK, Rainer. Pedagogia da Bauhaus. São Paulo: Martins Fontes, 1989. 